\title{
Sensory Properties of Fats and Fat Replacements
}

\author{
Adam Drewnowski, Ph.D.
}

The typical American diet derives $37 \%$ of total daily energy intake from fat. ${ }^{1}$ Fat consumption in the U.S. has been estimated at $98 \mathrm{~g} /$ day for men and 65 $\mathrm{g} /$ day for women. ${ }^{1}$ Diets low in carbohydrate and fiber but rich in fat have been associated with high prevalence of obesity and elevated risks of coronary artery disease and some forms of cancer. ${ }^{2,3}$ Current nutritional guidelines recommend reducing fat consumption to $30 \%$ or less of total daily energy intake. ${ }^{2,3}$

However, reducing fat consumption is no easy task. People generally like the taste of fatcontaining foods and are reluctant to give them up. Poor adherence to very-low-fat diets is a documented problem in the dietary management of plasma lipid disorders, ${ }^{4}$ while cravings for sweet desserts are a major obstacle to weight reduction. Even highly motivated patients prove resistant to diets composed entirely of vegetables, fruit, cereal grains, and low-fat meats.

Why are fat-containing foods so difficult to give up? The nutritional role of fats is to provide a concentrated source of energy and to supply essential fatty acids and fat-soluble vitamins to the diet. ${ }^{5}$ However, it is the sensory properties of fats that make a diet flavorful, varied, and rich. Fats are responsible for the texture, mouthfeel, and flavor of many foods, and they play a major role in determining the palatability of the diet. ${ }^{6}$

\section{Sensory Properties of Fats}

Fats in foods provide a wide variety of oral sensations. Dairy fat in ice cream contributes to product smoothness by preventing the formation of large ice crystals. Water-binding properties of fats in bakery goods are responsible for the sensation of freshness and moisture. The marbling of meat contributes to its tenderness. Frying in fat brings foods to temper-

Dr. Drewnowski is a Professor of Community Health Programs and Director, Human Nutrition Program, School of Public Health, University of Michigan, Ann Arbor, MI 48109, USA. atures above the boiling point of water and contributes to crisp or crunchy textures in fried potatoes or potato chips. ${ }^{5-7}$

The first sensory response to fats involves olfactory perception through the nose or mouth of fatsoluble volatile flavor molecules. These compounds impart the characteristic flavor and aroma to many foods. Subsequent oral perception of fat is determined by food texture as sensed by the oral cavity during chewing and swallowing. ${ }^{6}$ The type of sensation or mouthfeel depends on the nature of the food product. For example, fat in dairy products takes the form of emulsified globules that are not individually perceived by the oral cavity; instead, the substance feels creamy. ${ }^{7}$ Thus, the principal oro-sensory cues for fat content in milk and cream are stimulus thickness, smoothness, and viscosity. ${ }^{6,7}$ More viscous stimuli are generally perceived as more desirable and rich in fat content. Accordingly, the illusion of fat mouthfeel can be created through the use of microparticulated proteins, gelatin-based stabilizers, or other thickeners that enhance the perceived smoothness or creaminess of the food product. ${ }^{8}$ A newly-approved fat substitute, Simplesse $^{\mathscr{O}}$ (The NutraSweet Company), consists of spherical protein microglobules designed to emulate the cooling mouthfeel of emulsified dairy fat. ${ }^{8}$

Food texture is an important sensory attribute. In describing foods, people tend to describe texture qualities rather than taste or flavor. ${ }^{9}$ Among key words defining the texture of foods are: hard, soft, juicy, chewy, greasy, viscous, slippery, creamy, crisp, crunchy, and brittle. ${ }^{9}$ Cognitive studies based on multivariate factor analysis of texture terms revealed the following principal dimensions of food texture: hard/soft, cold/warm, oily/juicy, elastic/ flaky, and heavy, viscous, and smooth. ${ }^{10}$ Each of these textural dimensions can be influenced by the fat content of foods.

The General Foods Texture Profile has long been the standard industry method for evaluating food texture. ${ }^{11,12}$ This procedure, developed in the 1960 s, treated texture evaluation as a dynamic analysis of the mechanical, geometrical, fat, and moisture qualities of food. The analysis was conducted 
Percent Energy from

\begin{tabular}{llllll} 
& & & & \multicolumn{2}{l}{ Carbohydrate } \\
\cline { 5 - 6 } & Kcal per Serving & Protein & Fat & Simple & Complex \\
\hline Ice cream (16\% fat) & 349 & 4.7 & 61.0 & 37.3 & 0.0 \\
Chocolate/peanut candies & 177 & 8.9 & 45.1 & 37.0 & 8.9 \\
Chocolate candy bar & 161 & 4.1 & 49.7 & 41.8 & 4.2 \\
\hline
\end{tabular}

along the dimension of time, from first bite to complete mastication and swallowing. The primary mechanical characteristics of foods were initially defined as hardness, cohesiveness, adhesiveness, and viscosity, while secondary characteristics included brittleness, chewiness, and gumminess. ${ }^{11.12}$ Geometrical characteristics were defined as those related to the shape, size, and orientation of food particles (gritty, grainy, coarse), whereas mouthfeel was related to the perception of moisture or fat (wet, oily, greasy).

Because fats endow foods with so many taste and textural qualities, oro-sensory assessment of fat content can sometimes be unreliable, especially in solid foods. It is not always clear what sensory cues contribute the most to the overall perception of "fatness" and how these percepts in turn relate to sensory preferences for high-fat foods.

\section{Invisible Fats}

Fats in the diet are usually described as visible or invisible fats. Visible fats include butter, margarine, spreads, and cooking oils. Invisible fats are defined as those in milk, meat, and cheese, and those added to foods during processing. ${ }^{5}$ However, there are other foods, particularly sweet desserts, where fat also behaves as invisible calories. Since oral assessment of fat content is often difficult, attention tends to focus on the more salient sensory ingredient, sugar. ${ }^{13}$ Consequently, ice cream, chocolate, and other sweet desserts are often thought of as sugary and therefore carbohydrate-rich foods. For example, recent literature on food preferences in obesity and seasonal affective disorder (SAD) reported several instances of a specific appetite for a single macronutrient, carbohydrate. ${ }^{14-16}$ Widespread "carbohydrate cravings" were said to be associated with a deficiency of a central neurotransmitter, serotonin. ${ }^{14}$ Selective consumption of carbohydraterich snacks in the absence of protein was said to redress serotonin imbalance and alleviate depression and fatigue. ${ }^{14,15}$ Selection of carbohydrate-rich foods by susceptible obese patients was accordingly described as an unconscious attempt at selfmedication. ${ }^{15}$
The problem was that the "carbohydrate-rich" snacks used in many previous studies have included chocolate candies, chocolate cupcakes, and even vanilla ice cream sundaes with whipped cream. ${ }^{14,17}$ Indeed, the very term "carbohydrate craving" was originally described as a "ravenous appetite for a variety of sweet substances including chocolate, cake, pastry, and ice cream." 18 Such foods are largely composed of two key ingredients, sugar and fat. They may be more properly described as sugar/fat mixtures. As shown in Table 1, fat rather than sugar supplies the bulk of the calories in chocolate candy bars and ice cream. The use of the term "carbohydrate craving" to describe food preferences in obesity may be, therefore, misleading. Far from craving a single macronutrient, carbohydrate, many obese patients may show enhanced sensory preferences for foods rich in fat, sugar, or both.

\section{Sensory Preferences for Sugar and Fat}

Many obese patients show elevated sensory response to those sweet foods that are rich in fat. Our early studies assessed relative sensory preferences for sugar versus fat in a liquid model-food system composed of different proportions of milk, cream, and sugar. ${ }^{19}$ The studies were conducted with clinical populations of obese women, anorectic patients, and age-matched female controls. ${ }^{20,21}$ The subjects rated perceived sweetness, creaminess, and fat content of 20 different sugar/fat mixtures and judged the acceptability of each sample using nine-point category scales. The use of a mathematical modeling technique known as the Response Surface Method (RSM) helped to predict the shape of the sensory pleasure response as a function of stimulus ingredient levels. ${ }^{20,21}$

Hedonic response profiles were strongly interactive. While the acceptability of unsweetened dairy products was relatively low, the addition of sugar made the products highly appealing. However, ingredient composition of the optimally preferred mixture differed sharply among subject groups. While obese women preferred stimuli that were rich in fat but contained relatively little sugar, 
anorectic women liked sweet taste but disliked the oral sensation of fat. ${ }^{20,21}$

It should be noted that preferences for high-fat foods need not be linked to accurate or even conscious assessment of fat content. Our studies have also shown that subjects presented with solid mixtures of sugar and fat (blends of cottage cheese and cream cheese with sugar) were sometimes unable to distinguish between the low- and high-fat stimuli. ${ }^{22}$ However, highest preference ratings were obtained for those stimuli that were rich in fat. Consumers selecting high-fat foods need not be aware of their elevated fat content.

\section{Preferences for High-Fat Foods}

High-fat foods are among the core items of the American diet. ${ }^{23}$ Studies of food preferences in a large sample of Army personnel ${ }^{24}$ showed that steak, milk, and french fries were among the top food choices. In a more recent clinical study, obese men and women listed meat dishes, doughnuts, white bread, and ice cream among their ten favorite foods. Women were more likely to express preferences for doughnuts, bread, and chocolate, while men tended to list steak, hot dogs, sausage, and eggs. Although obese patients are said to crave carbohydrates, preferences for high-fat dishes are often closer to the mark. Preferences for carbohydrate-rich foods appeared restricted to obese women and were, moreover, limited to those foods that were sweet or were also major sources of fat. Preference for dietary fats may be a characteristic feature of human obesity syndrome. ${ }^{20}$ Since overweight people are the ones who require nutrition intervention for both weight control and heart disease, their elevated preferences for fat-rich foods are a matter for serious concern.

\section{Fat Replacements}

Strategies for reducing dietary fats must be planned carefully. The conventional dietary advice is to replace fats with low-calorie fruits, vegetables, and grains. However, a diet devoid of fats seldom tastes good and consumers have become adept at replacing one source of fat with another. For example, nutritional survey studies conducted by the United States Department of Agriculture (USDA) show that the consumption of meat by women dropped by $34 \%$ between 1977 and $1985 .{ }^{25}$ Similarly, the consumption of milk and eggs dropped by a third during that period. However, the consumption of mixed dishes containing meat (mostly sandwiches and stews) increased by $35 \%$ between 1977 and 1985, while the consumption of skim and low-fat milk increased by as much as $60 \%$. The consumption of cheese and frozen desserts also increased substantially. It appears that consumers have learned to avoid overt sources of fat (meat, butter, and milk), replacing them with food products in which the presence of fat is either less obvious or more difficult to detect by sensory means.

The food industry's search for intense sweeteners has given way to a new emphasis on fat replacements. This involves some complex technological problems. A successful fat-replacement product must replicate the texture, mouthfeel, and flavor of the original fat. In the past, this has been accomplished by using mixtures of starch, protein, and water. Fat substitutes used in such products as margarine, frozen desserts, dips, salad dressings, cake frostings, and imitation sour cream were typically based on modified starches and gums. These products are partially or fully digestible and provide between 1 and $4 \mathrm{kcal} / \mathrm{g} .{ }^{8}$ One example of a fat substitute is polydextrose (Pfizer), a bland, partiallyabsorbable starch polymer that supplies some of the mouthfeel qualities normally provided by sugar and fat. ${ }^{13}$ Polydextrose has been used as a partial fat substitute in frozen desserts, puddings, and cake frostings, supplying approximately $1 \mathrm{kcal} / \mathrm{g}$. Other starch-based fat replacements withstand processing at high temperatures to form gels with a smooth, fat-like texture. These products have been used in fat-free bakery goods, meat products, and confections.

Mixtures of protein and water have also served as fat replacement products. Microparticulated proteins are composed of egg albumin and casein. The small, round particles resemble those of emulsified dairy fat in size and shape. Since food particles less than $3 \mu \mathrm{m}$ in diameter are not individually detected by the tongue, the substance has an overall creamy feel. ${ }^{8}$ Microparticulated proteins can replace some or all of the fat in ice cream, creamy-style salad dressing, margarine, and other food products that contain dairy fat or other fats in products that are not cooked. Although they are created using heat, microparticulated proteins, like regular proteins, coagulate at high temperatures and lose their creaminess. Because their globular structure traps water, they contain only one or two calories per gram as opposed to nine calories per gram for fat and four calories per gram for carbohydrates or protein. $^{8}$

Other fat replacement products still in the development phase are based on altered fats that are not absorbable and so provide no energy. Olestra ${ }^{\odot}$ (Procter and Gamble) is the name of a product composed of sucrose esterified with six to eight fatty acids derived from soybean, corn, or cottonseed oils. The resultant molecule is too bulky to be digested by lipases and is not absorbed or metabo- 
lized by the body. Since the product is heat stable, it is intended to replace fat used in cooking and frying. As yet, this fat replacement has not been approved by the Food and Drug Administration (FDA).

\section{Conclusions}

Recent public health reports have implicated dietary fat as a major causal factor in the development of chronic disease. However, the conventional recommendations to consume less fat and more grains, vegetables, and fruit have not been fully effective. High-fat foods are an important component of the American diet and preferences for dietary fats are hard to break. New strategies may include fat replacement products that offer the same eating pleasure as high-fat foods, without providing excessive energy.

1. Nutrition monitoring in the United States. Washington, DC: US Dept of Health and Human Services; US Dept of Agriculture, 1989; DHHS publication no. (PHS) 89-1225

2. The Surgeon General's Report on nutrition and health. Washington, DC: US Dept of Health and Human Services, 1988; DHHS publication no. (PHS) 88-50210

3. Food and Nutrition Board, National Academy of Sciences. Diet and Health. Washington DC: National Academy Press, 1989

4. Ernst N, Levy RI. Diet, hyperlipidemia and atherosclerosis. In: Goodhart RS, Shils ME, eds. Modern nutrition in health and disease. 6th ed. Philadelphia: Lea \& Febiger, 1980:1045-70

5. Schneeman B. Fats in the diet: Why and where? Food Technol 1986;40:115-20

6. Drewnowski A. Fats and food texture: sensory and hedonic evaluations. In: Moskowitz HR, ed. Food texture. New York: Marcel Dekker, 1987:251-72

7. Cooper HR. Texture in dairy products and its sensory evaluation. In: Moskowitz HR, eds. Food texture. New York: Marcel Dekker, 1987:217-50

8. Drewnowski $A$. The new fat replacements. A strategy for reducing fat consumption. Postgrad Med 1990;87:111-21

9. Szczesniak AS. Consumer awareness of texture and other food attributes. J Texture Stud 1971;2:196-206

10. Yoshikawa S, Nishumaru S, Yoshida M. Collection and classification of words for description in food texture, III: Classification by multivariate analysis. $\mathrm{J}$ Texture Stud 1970;1:452-63

11. Brandt MA, Skinner EZ, Coleman JA. Texture profile method. J Food Sci 1963;28:404-9

12. Civille GV, Liska $\mathbb{I H}$. Modifications and applications to foods of the General Foods sensory texture profile technique. J Texture Stud 1975;6:1931

13. Drewnowski A, Schwartz M. Invisible fats: sensory assessment of sugar/fat mixtures. Appetite 1990;14:203-17

14. Wurtman JJ, Wurtman RJ, Growdon JH, Henry P, Lipscomb A, Zeisel SH. Carbohydrate craving in obese people: suppression by treatments affecting serotoninergic transmission. Int $\mathrm{J}$ Eating Disorders $1981 ; 1: 2-15$

15. Lieberman HR, Wurtman JJ, Chew B. Changes in mood after carbohydrate consumption among obese individuals. Am J Clin Nutr 1986;44:772-8

16. Rosenthal NE, Genhart M, Jacobsen FM, Skwerer RG, Wehr TA. Disturbances of appetite and weight regulation in seasonal affective disorder. Ann NY Acad Sci 1987;499:216-30

17. Chiodo J, Latimer PR. Hunger perceptions and satiety responses among normal-weight bulimics and normals to a high-calorie, carbohydrate-rich food. Psychol Med 1986;16:343-9

18. Paykel ES, Mueller PS, De la Vergne PM. Amitriptylline, weight gain and carbohydrate craving: a side efect. Br J Psychiatry 1973;123:501-7

19. Drewnowski A, Greenwood MRC. Cream and sugar: human preferences for high-fat foods. Physiol Behav 1983;30:629-33

20. Drewnowski A, Brunzell JD, Sande K, Iverius PH, Greenwood MRC. Sweet tooth reconsidered: taste responsiveness in human obesity. Physiol Behav 1985;35:617-22

21. Drewnowski A, Halmi KA, Pierce B, Gibbs J, Smith GP. Taste and eating disorders. Am J Clin Nutr 1987;46:442-50

22. Drewnowski A, Shrager EE, Lipsky C, Stellar E, Greenwood MRC. Sugar and fat: sensory and hedonic evaluation of liquid and solid foods. Physiol Behav 1989;45:177-83

23. Block G, Dresser CM, Hartman AM, Carroll MD. Nutrient sources in the American diet: quantitative data from the NHANES II survey. Am J Epidemiol 1985; $122: 27-40$

24. Meiselman HL, Waterman D, Symington LE. Armed Forces Food Preferences. Natick, Massachusetts: US Army Natick Development Center Tech Rep 75-63-FSL

25. Putnam JJ. Food consumption. National Food Review 1990; July-Sept: 1-9 